\title{
AUTO-ESTIMA PARA APROPRIAÇÃO DO SABER
}

\begin{abstract}
Aquisição do conhecimento é um processo que envolve a integridade das experiências das crianças na família e na escola
\end{abstract}

$\mathrm{F}$

oi em 1998 que priorizei trabalhar com os alunos do ensino fundamental duas vertentes: auto-estima e domínio de saberes. O objetivo foi o de criar meios que facilitassem a troca de experiências entre as crianças. Este trabalho, naturalmente, foi fruto de estudos, experimentos e práticas fundamentadas em teorias socioconstrutivistas'.

Durante o projeto, o trabalho junto às crianças foi favorecido pela extrema boa vontade, compromisso e responsabilidade da direção da Escola, que participou contribuindo com diferentes maneiras de orientar, estimular e incentivar seus professores à realização de seu trabalho diário.
No início do ano letivo, os professores organizam um calendário de atividades onde incluem seus projetos. No plano da escola existe uma proposta mais abrangente conhecida por Mostra de Ciências e Cultura, momento para apresentação de atividades escolhidas por cada professor. Essa Mostra tem características de feira e é realizada no final do segundo semestre (outubro/novembro). Na elaboração do calendário, os professores também decidem qual tema desejam apresentar na Mostra. Normalmente, estão relacionados aos conteúdos escolares e a temas contemporâneos. Podemos realizar pesquisas sobre os temas dos projetos durante todo o

1. "As teorias construtivistas representam um esforço na busca de caminhos que dêem conta da complexidade do processo de aprendizagem. (...) prevalece a orientação antropológica histórico-social, pela qual o ser humano se faz na interação social...". Seus principais representantes teóricos são: Jean Piaget, Lev Semenovich Vygotsky e Emilia Ferreiro. Referência extraída de: ARANHA, Maria Lúcia de Arruda. Filosofia da educação. 2. ed. São Paulo: Moderna, 1996. p. 202. (N. Ed.) 
ano letivo. Ressalto que a ausência de estímulo impossibilita a realização de bons trabalhos por parte dos professores.

\section{OBJETIVOS E ATIVIDADES}

O objetivo do projeto foi o de levar a criança a perceber e praticar atitudes solidárias e afetivas, contribuindo, com sua postura acolhedora, com o processo de apropriação de diferentes saberes. Garantir, assim, uma aprendizagem mais tranqüila e segura, principalmente no espaço escolar, onde o aluno manifesta muitas características de baixa auto-estima, em geral resultante de um tratamento inadequado dos adultos responsáveis por seu desenvolvimento.

$\mathrm{O}$ projeto envolveu pais, professor e alunos. Primeiro conversamos sobre o que aconteceria na Mostra. Iniciamos por investigar sinais do nosso tema de trabalho a partir das experiências vivenciadas em sala de aula. Quem ainda não escreve e lê? Por que algumas crianças respondem de uma maneira hostil às ordens dadas à classe? O que leva certas crianças a apresentarem atitudes violentas com o colega? Essas primeiras indagações forneceram os dados para o nosso trabalho. Partindo dessas informações, desenvolvemos a linha de pesquisa que constou da elaboração de atividades relativas ao registro dos sinais e marcas da origem das crianças e do grupo com o qual elas convivem.

As atividades foram elaboradas basicamente a partir de questões para discussão com os pais e pesquisas realizadas junto às famílias. Estimulou-se a percepção de fatos que aconteciam com as crianças, sem- pre com o cuidado de valorizar suas referências e ampliando sua auto-estima. As respostas das atividades eram corrigidas no dia seguinte, tendo como leitor a professora ou a criança. Essas atividades ficavam coladas nos cadernos de lição de casa como bilhetes. As crianças habituaram-se a realizar lições de casa e seguiam esse ritual constante, criando organização e hábito de estudo. Tais lições eram realizadas de segunda a quinta-feira.

\section{MODELO DO BILHETE:}

\section{1-Cabeçalho}

2-Converse com seus pais ou responsáveis e escreva ou desenhe quem escolheu seu nome. 3-Qual o significado de seu nome?

Não esqueça, você já sabe, use letra maiúscula, minúscula, parágrafo e ponto final.

\section{Brilhe, muito, sempre! Um beijo, da prô!}

É muito importante notar que o professor alfabetizador exercita a prática interdisciplinar no seu dia-a-dia. Creio que isso conduz a uma contínua reflexão sobre todas as coisas. Ele é um pensador do cotidiano e do seu tempo: que cumpre o seu ofício verdadeiro, alimenta-se e se dilui entre as pessoas comuns, essas mesmas que estão em pequenos grupos, em inúmeras salas de aulas.

\section{TEATRO DE FANTOCHES, TELEVISÃO, FILME}

Resolvemos, após conversa dirigida, que o projeto teria o perfil de um progra- 
ma de televisão: então, usamos o teatro de fantoches para fazer de conta que era uma televisão.

Assistimos a um filme sobre a reprodução de diversos animais e fomos apontando as diferenças entre a reprodução deles e a humana.

\begin{tabular}{c}
\hline O amor foi um ponto \\
importante na nossa discussão \\
sobre reprodução e ponto de \\
partida para começarmos a \\
reconhecer o que era afinal a \\
auto-estima.
\end{tabular}

Os materiais necessários para montagem do estande foram trazidos pelos alunos ou produzimos em aula. Para mostrar nossa representação utilizamos espelhos, papel crepom, fitas de tecidos, fitas adesivas, canetinhas hidrocor, porta canetas, papel laminado, suporte para canetinhas, cesta para colocar os bilhetes de trocas de sentimentos, bilhetinhos com diversos sentimentos positivos, pirulitos em forma de coração, xerox de mensagens sobre auto-estima, cartolinas, cordonetes para fazer crachás, pregos (para segurar um grande espelho que foi colado dentro da cabine azul, onde as pessoas viam suas imagens e liam a mensagem sobre auto-estima), xerox de imagens que representavam cenas de auto-estima, placas de isopor para fixar as fotos dos alunos com registros de momentos importantes da vida da criança (a criança que não tinha foto a professora fotografou em algum momento da elaboração do trabalho), papel camurça (para fazer e recortar as letras para o nome do programa e fixá-lo na estrutura do tea- tro), cartaz com desenho da fecundação, mensagens escritas em computador com características de manchete, álbum de papel canson para registros de nomes e impressão digital, cartolina branca para a confecção de corações com mensagens fraternas, estrelinhas douradas (fechando o diploma contendo escrita de sentimentos positivos) e adesivos coloridos para representar as emoções dos visitantes.

Os pirulitos, as mensagens em diplomas, corações, os adesivos coloridos e as estrelas douradas foram entregues como brindes aos visitantes da mostra.

Essa montagem só foi possível graças à cumplicidade, ao compromisso e a muita boa vontade de todos os envolvidos, direta ou indiretamente no projeto.

\section{DINÂMICAS DO PROJETO}

Após assistirmos ao filme Reprodução ${ }^{2}$, criamos um espaço para conversa e colocação de relatos. As crianças falavam tudo o que lembravam sobre o assunto em questão. As atividades normalmente eram realizadas em grupo ou em duplas.

Na leitura das lições de casa, representávamos como tinham acontecido as pesquisas em casa. Era muito enfatizada a atitude dos adultos que respondiam com carinho e interesse às pesquisas das crianças. Ao entregarem as fotos, os alunos trocavam idéias, brincavam, faziam fofocas. Denominamos essa atividade descontraída de fofoca no $a r$. A intenção era despertar a curiosidade pelo outro colega. Sempre havia o cuidado de colocar as crianças mais seguras emocionalmente próximas ao coleguinha que apresentava algum tipo de insegurança.

2. Reprodução: produção e direção de Bárbara Burst; edição David Hil; texto Nigel Henbest. Discovery Channel: Super Interessante. v. 5. Abril Vídeo. Duração 25 minutos, 1995. 


\section{Troca de Sentimentos}

Brincamos de troca de sentimentos. Em círculo, olhando um para o outro e apertando a mão dizíamos: "Vamos trocar um sentimento?" Procuramos evidenciar sempre os sentimentos positivos. Era como trocar figurinhas.

\section{Hora do abraço}

Tendo o professor como mediador, em círculo, as crianças manifestavam-se quando sentiam algo de triste. Imediatamente, um colega levantava a mão e dizia que poderia dar um abraço, para que aquela sensação triste passasse. Isso acontecia até que todos tivessem a chance de trocar um abraço. Essa atividade foi realizada durante os vinte dias da pesquisa e tornou-se prática até o final do ano, sempre nos últimos momentos da aula.

\section{Ajuda}

Durante o decorrer das aulas, as crianças tentavam ajudar um colega que apresentava dificuldades no domínio dos conteúdos escolares, sempre após ter realizado suas atividades do dia. Essa atitude foi de grande importância, surgindo muitas conquistas em relação à confiança e à autonomia de muitos alunos com baixa auto-estima.

\section{APRESENTAÇÃO DO PROJETO NA MOSTRA}

Foi elaborado roteiro com as falas das crianças e, a partir dele, ensaiávamos o nosso programa: "Você é um tesouro."

Nosso estande foi organizado em estações com caracterização própria, de acordo com as diferentes falas das crianças. Elas foram organizadas em equipes para que todas pudessem participar das apresentações. Para a montagem concreta do estande, contamos com a doação de muitos materiais dos pais das crianças, da professora, de parentes e amigos da professora.

\section{Estações do estande:}

Teatro de fantoche "a televisão"

Fala das crianças:

CRIANÇA - A - Nós somos da primeira série "B" e gostaríamos de pedir sua participação na nossa Feira de Ciências e Cultura.

CRIANÇA - B - Você saberia responder qual sentimento você tem bastante

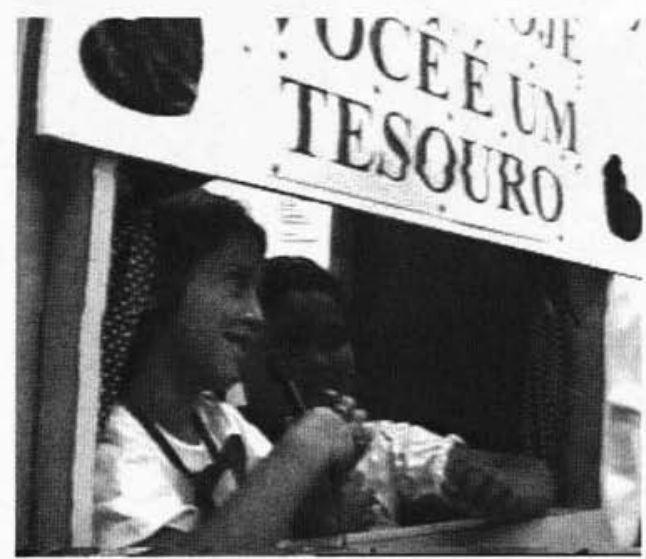

Na cabine azul, as crianças mostravam: você é um teouro.

e que poderia doar um pouco para ajudar as pessoas a conviverem melhor umas com as outras?

CRIANÇA - Entre e reconheça um tesouro único e sem igual em qualquer parte do mundo. 
Leia o bilhete fixado ao espelho da cabine azul:

"Você se lembra? Em algum lugar do passado, um e apenas um espermatozóide fecundou um óvulo, e nesse momento você participou da maior competição da vida e venceu!

Venceu para conquistar uma vida inteirinha que Deus lhe deu e a graça de ter nascido com um corpo sadio, perfeito e capaz de realizar coisas incríveis e fantásticas.

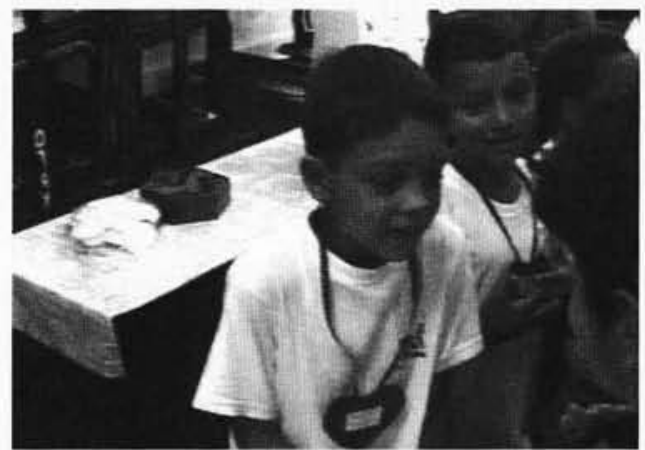

Os meninos levaram a sério o trabalho com o público da mostra.

Oespírito da conquista está dentro de você. Você foi feito para dar certo, para ser feliz e para conquistar seus sonhos e objetivos."

Com muito amor! Primeira série "B"

\section{Espelhos}

CRIANÇA - A - Em cada espelho que você olha, você descobre algo bom dentro de você. Assim aumenta sua auto-estima.

CRIANÇA - B - Você sabe o que é autoestima? É quando começo a descobrir os meus valores e as minhas qualidades.

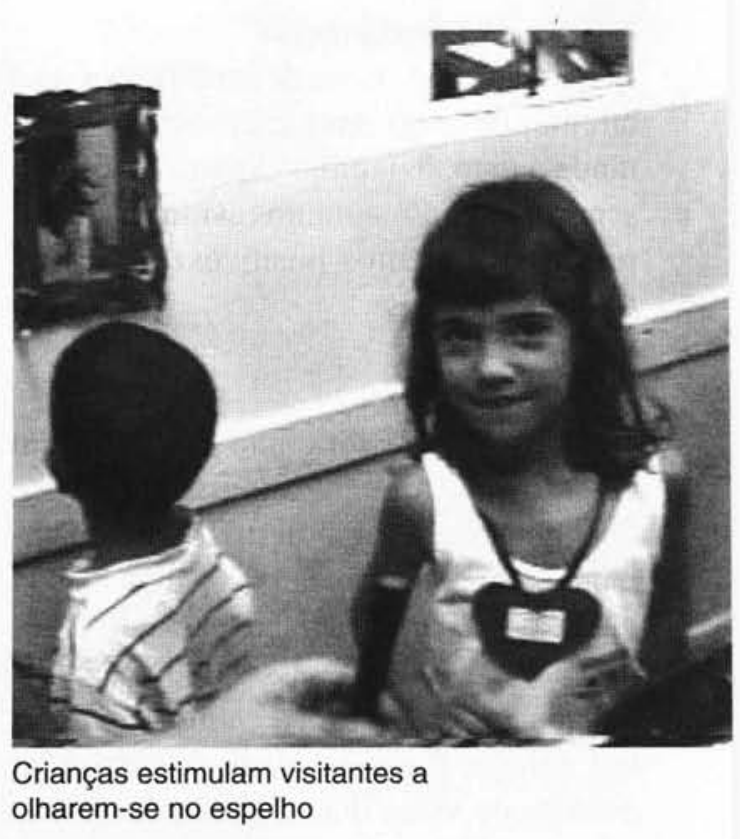

Painel de fotos

CRIANÇA - A - Aqui nós temos registros que mostram o quanto os pais gostam de seus filhos.

CRIANÇA - B - Esse tipo de coisa ajuda a criar auto-estima.

CRIANÇA - Cada um de nós é único no mundo, temos uma identidade e sentimentos próprios.

\section{Espelhos médios}

CRIANÇA - A - Nossa idéia é ajudar as pessoas a perceberem o quanto elas são lindas e maravilhosas.

CRIANÇA - B - Descubra a grandeza que existe dentro de você para estimar e contribuir na convivência entre as pessoas. Assim, as pessoas podem viver mais alegres, sadias e felizes. 


\section{Álbum de registros}

CRIANÇA - Deixe aqui o sinal de sua identidade e seu nome.

\section{Cesta de sentimentos}

CRIANÇA - Troque aqui um sentimento muito usado por outro bem novinho.

\section{Revelando meu estado emocional}

CRIANÇA - Você está alegre ou triste? A partir da resposta, a criança fixa um adesivo: laranja para emoções alegres e verde para tristezas. Obrigado pela sua participação.

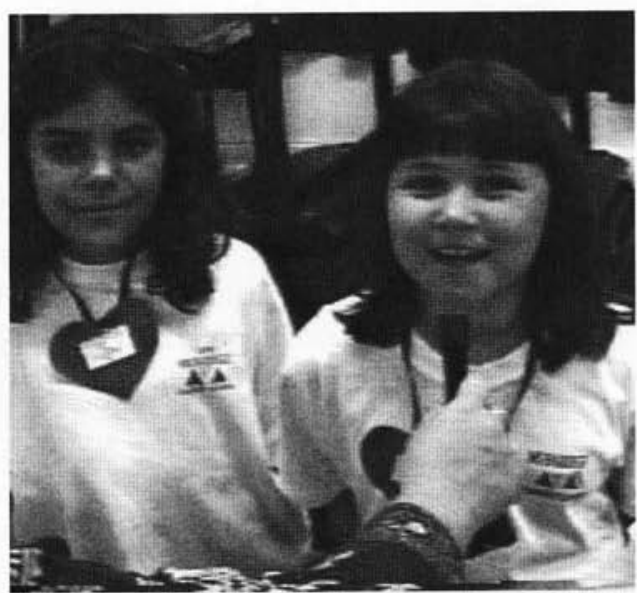

Meninas agradecem aos participantes da mostra.

Resumo: Professora da primeira série do ensino fundamental trabalha para elevar a autoestima das crianças, criando ambiente favorável - sensível, positivo, amigável - e com isso melhorar a apreensão dos conteúdos disciplinares, relacionando-os com a vida concreta. $\mathrm{A}$ professora desenvolve seu projeto ao longo do ano letivo e o apresenta, de forma criativa, na Mostra de Ciências e Cultura da escola.

Palavras chave: auto-estima, família, escola, aprendizagem, ensino fundamental

Abstract. A first grade teacher, the author works at elevating the children's self-esteem, creating a favorable environment - one that is sensitive, positive, friendly - and, by this, she aims at improving the reception of class content, relating it to the children's concrete life. The teacher carries out her project throughout the school year and presents it, in a creative manner, at the school's Science and Culture fair.

Key words: self-esteem, family, school, learning, fundamental teaching 